\title{
Efficient production of I-menthol in a two-phase system with SDS using an immobilized Bacillus subtilis esterase
}

\author{
Jiang Pan ${ }^{1}$, Ngoc-Duy Dang ${ }^{1}$, Gao-Wei Zheng ${ }^{1 *}$, Bo Cheng ${ }^{2}$, Qin Ye ${ }^{1}$ and Jian-He Xu*
}

\begin{abstract}
Background: levo-Menthol is an important flavoring chemical, which can be prepared by enantioselective enzymatic hydrolysis of $d$-menthyl esters. A recombinant esterase (BsE) cloned from Bacillus subtilis 0554 shows excellent enantioselectivity to $\mathrm{dl}$-menthyl acetate and has been immobilized using cross-linked enzyme aggregates. Though BsE has relatively high substrate tolerance, the conversion of $d$-menthyl acetate decreased sharply with the increase of substrate loading from 1 to $3 \mathrm{M}$ in mono-aqueous system, which might be due to the severe inhibition of enzyme activity at extremely high load of substrate or product. In this work, enzymatic hydrolysis of dl-menthyl acetate with an extremely high load using the immobilized CLEA-BsE was investigated in an organic-aqueous biphasic system containing surfactant to establish a promising bioprocess for large-scale production of I-menthol.

Results: An efficient biphasic reaction system of pentanol-water containing sodium dodecyl sulfate (SDS) was developed for improving enantioselective hydrolysis of $d$-menthyl acetate to produce $/$-menthol by immobilized BsE. Under the optimized reaction conditions, I-menthol was produced in $>97 \%$ enantiomeric excess (ee) at a substrate load of up to $3.0 \mathrm{M}$ with $>40 \%$ conversion.
\end{abstract}

Conclusions: All the positive features demonstrate the potential applicability of the bioprocess for the large-scale production of I-menthol.

Keywords: I-Menthol; Enantioselective hydrolysis; Organic-aqueous biphasic system; dl-Menthyl acetate; Immobilized Bacillus subtilis esterase

\section{Background}

Menthol is an important cyclic monoterpene alcohol having eight optical isomers because of three chiral centers. Among them, $l$-menthol is not only one of the most important flavoring chemicals used extensively in oral products, pharmaceuticals, tobacco products, confectionaries, and shaving products [1,2], but also a useful chiral resolving reagent $[3,4]$. In the past two decades, the global demand for $l$-menthol increased sharply from 6,300 to $20,000 \mathrm{t}$ [5], and the production of $l$-menthol by extracting from mint can no longer meet the market demands. Therefore, considerable efforts have been

\footnotetext{
* Correspondence: gaoweizheng@ecust.edu.cn; jianhexu@ecust.edu.cn 'Laboratory of Biocatalysis and Synthetic Biotechnology, State Key Laboratory of Bioreactor Engineering, East China University of Science and Technology, 130 Meilong Road, Shanghai 200237, China

Full list of author information is available at the end of the article
}

devoted to the production of $l$-menthol by synthetic or semi-synthetic method.

Symrise Incorporation (Germany) first developed a chemical synthesis process for the industrial production of $l$-menthol using thymol as a raw material $[6,7]$. Later, Takasago International Corporation (Japan) developed an elegant route from myrcene based on the catalytic asymmetric isomerization of geranyldiethylamine by using a chiral catalyst (S)-BINAP-Rh, invented by Nobel laureate Ryoji Noyori. The production of $l$-menthol has reached $1,000 \mathrm{t}$ annually [8-11].

Though chemical synthesis has been successfully commercialized, biosynthetic methods still attract much attention due to the advantages of high activity, mild reaction condition, little pollution, and excellent purity of product, and more importantly, the $l$-menthol produced is much closer to the natural product. Researchers from South Africa have developed a biosynthetic process for preparation 
of $l$-menthol by lipase-catalyzed kinetic resolution of $d l$-menthol at a scale of kilogram [12,13]. Other biosynthetic approaches, including enantioselective esterification, transesterification, and hydrolysis, have also been reported [14-22]. In our laboratory, using racemic menthyl acetate as the sole carbon source and combining the strategy of habituated culture with increasing substrate concentration, a bacterial strain of Bacillus subtilis ECU0554 was isolated from soil samples, which exhibited very high substrate tolerance $\left(100 \mathrm{~g} \mathrm{l}^{-1}, 0.5 \mathrm{M}\right)$ and excellent enantioselectivity $(E>100)$ [23]. The esterase (BsE) catalyzing the enantioselective hydrolysis of $d l$-menthyl acetate was cloned and overexpressed in Escherichia coli [24]. The free BsE was not very stable, and its stability was improved by immobilization in the form of cross-linked enzyme aggregates (CLEAs) [25]. The thermostability of the immobilized $\mathrm{BsE}$ at $30^{\circ} \mathrm{C}$ was increased by 360 times, with only $8 \%$ activity loss after 10 cycles of repeated use in enzymatic resolution of $d l$-menthyl acetate.

The solubility of $d l$-menthyl acetate in mono-aqueous phase was very low, and ethanol was added as cosolvent to improve the substrate solubility [23]. Although BsE showed relatively high substrate tolerance, the conversion decreased sharply with increase of substrate concentration from 1 to $3 \mathrm{M}$ in mono-aqueous system, which might be due to the severe inhibition of enzyme activity at extremely high concentration of substrate or product. Organicaqueous biphasic system was usually adopted to increase the substrate load and relieve the substrate/product inhibition [26]. The addition of surfactant could facilitate the dispersal of the water-insoluble substrate through the formation of micellar system and improve the mass transfer of substrate [27], which is beneficial for the enzyme enantioselectivity [28]. As well known, the increase of substrate concentration can often effectively facilitate the downstream separation and reduce the cost of the product. Additionally, immobilized enzymes are insoluble in the reaction medium, thus avoiding contamination of the product, which is feasible for separation and simplifies the downstream process. Hence, in this work, enzymatic hydrolysis of $d l$-menthyl acetate at an extremely high load using the immobilized CLEA-BsE was investigated to establish a promising bioprocess for large-scale production of $l$-menthol.

\section{Methods}

\section{Materials}

$d l$-Menthol was purchased from Alfa Aesar (Tianjin, China), and $d l$-menthyl acetate was synthesized as described before [23]. All other reagents were obtained commercially and of analytic grade.

\section{Preparation of immobilized BsE}

The immobilized BsE was prepared as described previously [25]. The crude BsE (10 g powder) was dissolved in
$500 \mathrm{ml}$ potassium phosphate buffer (KPB, $100 \mathrm{mM}$, $\mathrm{pH}$ 7.0), then $250 \mathrm{~g}\left(\mathrm{NH}_{4}\right)_{2} \mathrm{SO}_{4}$ was added slowly with gentle stirring at $0^{\circ} \mathrm{C}$ and continuously stirred for $10 \mathrm{~min}$. A $25 \%$ glutaraldehyde solution $(12 \mathrm{ml})$ was added to the mixture. The suspension was stirred at $0^{\circ} \mathrm{C}$ for $3 \mathrm{~h}$, and the resultant immobilized $\mathrm{BsE}$ was separated by centrifugation $\left(6,000 \times g, 4^{\circ} \mathrm{C}, 5 \mathrm{~min}\right)$. After washing twice with $\mathrm{KPB}$, the collected immobilized BsE was lyophilized for later use.

For BsE activity assay, the BsE was appropriately diluted in $1.0 \mathrm{ml} \mathrm{KPB} \mathrm{(100} \mathrm{mM,} \mathrm{pH} \mathrm{8.0)} \mathrm{containing} 10 \mathrm{mM} \mathrm{dl}$ menthyl acetate and the reaction was performed at $30^{\circ} \mathrm{C}$, $1,000 \mathrm{rpm}$ for $10 \mathrm{~min}$. Then $500 \mu \mathrm{l}$ of reaction mixture was extracted with same volume of ethyl acetate, and the conversion of $l$-menthyl acetate was determined by gas chromatography (GC) analysis for the activity assay.

\section{Enzymatic hydrolysis of $d l$-menthyl acetate}

The reactions were performed in a $25-\mathrm{ml}$ jacketed reactor with $10 \mathrm{ml}$ of medium system. For mono-aqueous system, $\mathrm{KPB}$ (pH 8.0, $200 \mathrm{mM}$ ) containing 10\% ethanol was used, and for organic-aqueous biphasic system, the volumetric ratio of $\mathrm{KPB}(\mathrm{pH} 8.0,200 \mathrm{mM}$ ) and organic solvent was 4:1. $d l$-Menthyl acetate was added together with the immobilized BsE. Surfactant was also added in some cases. The reactions were performed at $30^{\circ} \mathrm{C}$ with magnetic stirring at $300 \mathrm{rpm}$. The $\mathrm{pH}$ of reaction mixture was controlled at 8.0 by automatically titrating $1 \mathrm{M} \mathrm{NaOH}$. Samples were withdrawn for GC analysis.

\section{Reaction scaling up}

Into a 250 -ml, three-necked flask, $59.4 \mathrm{~g} \mathrm{dl}$-menthyl acetate, $5.5 \mathrm{~g}$ immobilized BsE, $0.25 \mathrm{~g}$ SDS, $80 \mathrm{ml} \mathrm{KPB} \mathrm{(pH} \mathrm{8.0,}$ $200 \mathrm{mM}$ ), and $20 \mathrm{ml} n$-pentanol were added. The reaction mixture was incubated at $30^{\circ} \mathrm{C}$ and agitated at $300 \mathrm{rpm}$. The reaction $\mathrm{pH}$ was controlled at 8.0 by automatic titration of $1 \mathrm{M} \mathrm{NaOH}$. After a certain period of time, samples were withdrawn for $\mathrm{GC}$ analysis.

After $84 \mathrm{~h}$ of reaction, immobilized BsE was removed by filtration. The organic phase was separated and distilled under vacuum. A flash chromatography of the residue was performed on a silica column using a mobile phase of petroleum-ethyl acetate $(10: 1, v / v)$ to get chemically pure l-menthol.

\section{GC analysis}

GC analysis was performed as described previously [25]. The samples from the hydrolysis reaction mixture were analyzed on a GC-14 gas chromatography (Shimadzu, Kyoto, Japan) equipped with an FID detector. The enantiomeric excess of substrate $\left(\mathrm{ee}_{\mathrm{s}}\right.$ ) was determined using Beta Dex ${ }^{\mathrm{Tm}} 120$ chiral column $(30 \mathrm{~m} \times 0.25 \mathrm{~mm}, 0.25 \mu \mathrm{m}$ film thickness) from Supelco (Bellefonte, PA, USA) using $\mathrm{N}_{2}$ as carrier gas. The temperatures of column, injector, 
and detector were held at $130^{\circ} \mathrm{C}, 280^{\circ} \mathrm{C}$, and $350^{\circ} \mathrm{C}$, respectively. The enantiomeric excess of product $\left(\mathrm{ee}_{\mathrm{p}}\right)$ was determined using Gamma Dex 120 chiral column (30 m $\times$ $0.25 \mathrm{~mm}, 0.25 \mu \mathrm{m}$ film thickness) also from Supelco (USA) using $\mathrm{N}_{2}$ as carrier gas. The injector and detector temperatures were held at $280^{\circ} \mathrm{C}$ and $350^{\circ} \mathrm{C}$, respectively. The oven temperature was programmed from $110^{\circ} \mathrm{C}$, held for $15 \mathrm{~min}$, then raised to $150^{\circ} \mathrm{C}$ at a rate of $10^{\circ} \mathrm{C} \mathrm{min}{ }^{-1}$ and finally held at $150^{\circ} \mathrm{C}$ for $1 \mathrm{~min}$. The $\mathrm{ee}_{\mathrm{s}}$, ee $_{\mathrm{p}}$, substrate conversion, and enantioselectivity were calculated according to the equations of Chen et al. [29]. The conversion was calculated as $c=\mathrm{ee}_{\mathrm{s}} /\left(\mathrm{ee}_{\mathrm{s}}+\mathrm{ee}_{\mathrm{p}}\right)$ and the $E$ value was calculated as $E=\ln \left[1-c\left(1+\mathrm{ee}_{\mathrm{p}}\right)\right] / \ln \left[1-c\left(1-\mathrm{ee}_{\mathrm{p}}\right)\right]$.

\section{Results and discussion}

\section{Enzymatic hydrolysis of $d$ l-menthyl acetate in} mono-aqueous system

The activity (turnover number) of the free BsE was determined as $1,304 \mathrm{~s}^{-1}$ (towards $l$-menthyl acetate), and the activity recovery of the immobilized BsE was as high as $70 \%$. Immobilized BsE could efficiently catalyze the enantioselective hydrolysis of $d l$-menthyl acetate to produce $l$-menthol in mono-aqueous phase containing $10 \%$ ethanol. As shown in Figure 1, at a substrate concentration of $1.0 \mathrm{M}, 41 \%$ of the racemic substrate can be hydrolyzed within $8 \mathrm{~h}$. However, when the substrate loading was further increased to $3 \mathrm{M}$ with a constant ratio of $\mathrm{S} / \mathrm{C}$ (substrate/catalyst, $g / g$ ), the reaction proceeded fast at first, and then slowed down sharply. Finally, merely $23.7 \%$ of the substrate was converted, indicating extremely high concentration of the substrate or the product might probably inhibit the enzyme activity.

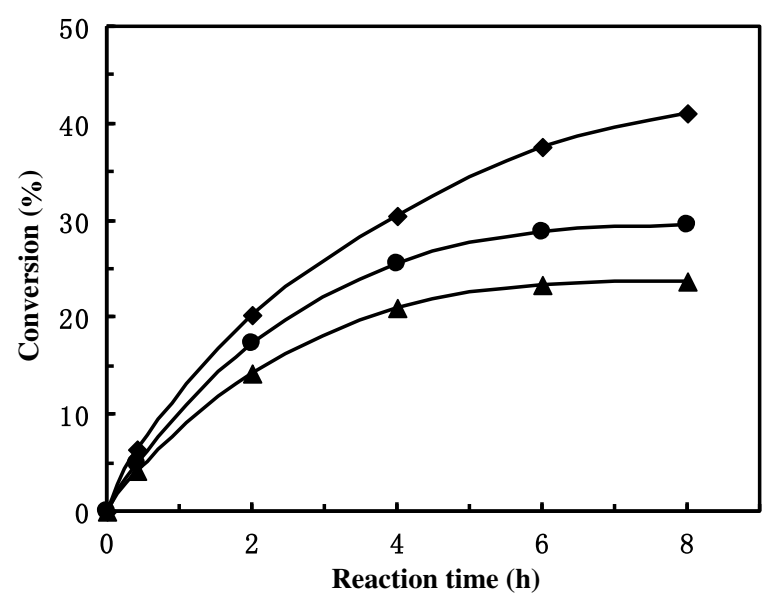

Figure 1 Enzymatic hydrolysis of $d l$-menthyl acetate at varied loads in mono-aqueous system containing $10 \%(v / v)$ of EtOH. Symbols: ( $1.0 \mathrm{M} \mathrm{dl}$-menthyl acetate with $55 \mathrm{~g} \mathrm{I}^{-1}$ of immobilized $\mathrm{BsE} ;(\bullet) 2.0 \mathrm{M} \mathrm{dl}$-menthyl acetate with $110 \mathrm{~g} \mathrm{I}^{-1}$ of immobilized BsE; ( $\mathbf{\Delta}) 3.0 \mathrm{M} \mathrm{dl}$-menthyl acetate with $165 \mathrm{~g} \mathrm{I}^{-1}$ of immobilized BsE. The reactions were performed at $30^{\circ} \mathrm{C}$ and $300 \mathrm{rpm}$.

\section{Enzymatic hydrolysis of $d l$-menthyl acetate in} organic-aqueous biphasic system

High loading of substrate is very important for biocatalysis since it can reduce the difficulties of product separation and facilitate practical application. However, exorbitant concentrations of the substrate or product may inhibit the activity of free and immobilized BsE, and consequently, prevent the completion of the enzymatic reaction.

The application of organic-aqueous biphasic systems has proven to be an efficient approach to solve the problem of inhibition [30,31]. In order to eliminate the inhibition of product $l$-menthol and realize the complete bioconversion of $l$-menthyl acetate at high loads, an organic-aqueous biphasic system was adopted as the reaction medium. Several water-immiscible organic solvents with varied log $P$ values were tested at a fixed phase ratio of $1: 4$ for organic solvent to buffer. The results were shown in Table 1.

Unfortunately, compared with the reaction in monoaqueous phase, the enantioselectivity ( $E$ value) of the immobilized BsE decreased obviously in organic-aqueous biphasic system. Even in the best system composed of $n$-pentanol and buffer, the $E$ value was only 26, far lower than that $(E=63)$ in mono-aqueous phase using $10 \%(v / v)$ ethanol as a cosolvent. The optical purity of the product also decreased from $94 \%$ ee to $85 \%$ ee. The decrease in enantioselectivity may be attributed to the diffusion limitation of substrate/product in the biphasic system. After the faster-reacting enantiomer ( $l$-menthyl acetate) in the microenvironment of the enzyme was completely converted, the fresh $l$-menthyl acetate could not swiftly access to the active site of the enzyme due to diffusion limitation. In this case, the enzyme would catalyze the hydrolysis of the slower-reacting $d$-menthyl acetate, thus decreasing the optical purity of the product (l-menthol).

Table 1 Enantioselective hydrolysis of dl-menthyl acetate by immobilized BsE in different organic-aqueous biphasic systems

\begin{tabular}{lllll}
\hline Organic solvent & $\boldsymbol{L} \boldsymbol{\operatorname { c o g } P}$ & Conversion (\%) & $\mathbf{e e}_{\mathbf{p}}$ (\%) & $\boldsymbol{E}$ value \\
\hline Control & & 41 & 94 & 63 \\
Methyl t-butyl ether & 1.3 & 39 & 81 & 17 \\
n-Pentanol & 1.5 & 44 & 85 & 26 \\
Pentyl acetate & 2.1 & 15 & 89 & 20 \\
Toluene & 2.5 & 44 & 78 & 15 \\
Carbon tetrachloride & 2.8 & 37 & 70 & 10 \\
n-Nonanol & 3.6 & 50 & 63 & 8 \\
n-Octane & 4.4 & 32 & 61 & 5 \\
n-Dodecane & 6.1 & 32 & 53 & 4
\end{tabular}

The biphasic reactions were performed by adding $1.98 \mathrm{~g}(10 \mathrm{mmol})$ of $d$-menthyl acetate and $0.55 \mathrm{~g}$ immobilized BsE into a mixture of $8 \mathrm{ml} \mathrm{KPB}(\mathrm{pH} 8.0,200 \mathrm{mM})$ and $2 \mathrm{ml}$ organic solvent at $30^{\circ} \mathrm{C}$ and $300 \mathrm{rpm}$ for $48 \mathrm{~h}$. The control reaction was performed in $10 \mathrm{ml} \mathrm{KPB}$ containing $10 \%(\mathrm{v} / \mathrm{v})$ ethanol. 
Table 2 Enantioselective hydrolysis of dl-menthyl acetate by immobilized BsE in biphasic pentanol-buffer system containing a certain surfactant

\begin{tabular}{|c|c|c|c|c|c|}
\hline Additive & Hydrophilic lypophilic balance (HLB) & Critical micelle concentration (CMC, $\mathrm{g} \mathrm{I}^{-1}$ ) & Conversion (\%) & $e_{p}(\%)$ & $E$ value \\
\hline Control & & & 44 & 85 & 26 \\
\hline Tween 80 & 15 & 6.0 & 43 & 87 & 29 \\
\hline Triton X-100 & 13.5 & 0.13 & 50 & 85 & 35 \\
\hline Span 60 & 4.7 & 7.0 & 45 & 87 & 32 \\
\hline SDS & 40 & 2.3 & 44 & 95 & 83 \\
\hline
\end{tabular}

The reactions were performed at $30^{\circ} \mathrm{C}, 300 \mathrm{rpm}$, at $\mathrm{pH}$ of 8.0 , by adding $1.98 \mathrm{~g} \mathrm{(10} \mathrm{mmol)} \mathrm{of} d$ l-menthyl acetate, $0.55 \mathrm{~g}$ immobilized BsE, and $15 \mathrm{mg}$ surfactant into a mixture of $8 \mathrm{ml} \mathrm{KPB} \mathrm{(pH} \mathrm{8.0,200} \mathrm{mM)} \mathrm{and} 2 \mathrm{ml} n$-pentanol for $48 \mathrm{~h}$.

Improvement of enantioselectivity by adding a surfactant to biphasic system

In order to increase the enantioselectivity of the biphasic reaction, surfactants were introduced into the reaction system to improve the mass transfer of the substrate [28]. Four different surfactants were tested, including Tween 80, Triton X-100, Span 60, and sodium dodecyl sulfate (SDS). As shown in Table 2, the enantioselectivities increased slightly with the addition of Tween 80 , Triton X-100, or Span 60, but the modulating effects were not so significant. Surprisingly, when $1.5 \mathrm{~g} \mathrm{l}^{-1}$ of SDS (an anionic surfactant) was added, the enantioselectivity of the enzymatic reaction was significantly enhanced from 26 to 83, resulting in remarkable improvement of $l$-menthol enantiopurity from $85 \%$ ee to $95 \%$ ee. The improvement of enantioselectivity by SDS was also described by Mori et al. [32]. The significant modulation of enantioselectivity is may be due to the fact that SDS has a very high HLB value and a relatively low critical micelle concentration (CMC), which is favorable for forming an oil-in-water emulsion and for solubilizing the hydrophobic $d l$-menthyl acetate in the dispersed organic phase of the SDS micelles in the aqueous phase. Therefore, SDS was selected for further investigation.

Subsequently, the amount of SDS as an additive was optimized. The CMC of SDS in an aqueous solution was about $8 \mathrm{mmol} \mathrm{l}^{-1}$ (ca. $\left.2.3 \mathrm{~g} \mathrm{l}^{-1}\right)$. As shown in Table 3, the optical purity of the product increased with the increase of SDS concentration up to $2.5 \mathrm{~g} \mathrm{l}^{-1}$, beyond the CMC of SDS, where the enantiomeric ratio ( $E$ value) reached 155 . As the SDS concentration further increased to $5 \mathrm{~g} \mathrm{l}^{-1}$, the

Table 3 Enantioselective hydrolysis of $d l$-menthyl acetate by immobilized BsE in biphasic pentanol-buffer system with varied concentrations of SDS

\begin{tabular}{llll}
\hline SDS concentration $\left(\mathbf{g ~}^{\mathbf{- 1}}\right)$ & Conversion $(\%)$ & $\mathbf{e e}_{\mathbf{p}} \mathbf{( \% )}$ & $\boldsymbol{E}$ value \\
\hline 0.5 & 47 & 91 & 52 \\
1.5 & 44 & 95 & 83 \\
2.5 & 41 & 97 & 155 \\
5.0 & 26 & 97 & 90 \\
\hline
\end{tabular}

The reactions were performed at $30^{\circ} \mathrm{C}$ and $300 \mathrm{rpm}$ for $48 \mathrm{~h}$ by adding $1.98 \mathrm{~g}$ (10 mmol) dl-menthyl acetate, $0.55 \mathrm{~g}$ immobilized $\mathrm{BsE}$, and a varied amount of SDS into a mixture of $8 \mathrm{ml} \mathrm{KPB} \mathrm{(pH} \mathrm{8.0,} 200 \mathrm{mM}$ ) and $2 \mathrm{ml}$-pentanol. enantioselectivity of the reaction did not increase obviously. On the other hand, the conversion decreased significantly, perhaps due to the denaturation/inactivation of the enzyme resulting from the existence of excessive SDS. Therefore, the optimal concentration of SDS was chosen as $2.5 \mathrm{~g} \mathrm{l}^{-1}$.

Under the above optimized conditions, the enantioselectivity of biohydrolysis was significantly enhanced. Enzymatic hydrolysis of $d l$-menthyl acetate at high concentrations of 1 to $3 \mathrm{M}$ was reexamined. As shown in Table 4, when the substrate loading was increased from 1 to $3 \mathrm{M}$, the final conversions were maintained at a high level (over $40 \%$ ) with a constant ratio of S/C, though the reaction time was extended to some degree. The optical purities of the produced $l$-menthol were also quite satisfactory, all better than $97 \%$ ee.

The initial reaction rate at various stirring rates was determined, as shown in Figure 2. When the stirring rate increased from 200 to $300 \mathrm{rpm}$, the reaction rate increased sharply from 23.8 to $77.8 \mathrm{mmol} \mathrm{l}^{-1} \mathrm{~h}^{-1}$; however, when the stirring rate further increased to $500 \mathrm{rpm}$, no obvious increase in the reaction rate was observed. Since the concentration of SDS has reached its CMC, normal micelles could be formed rapidly at a relatively high stirring rate, thereby facilitating the solubilization and diffusion of the hydrophobic substrate, which in turn will result in higher reaction rate. As a result, $300 \mathrm{rpm}$ was employed for further investigation.

The repeated use of the immobilized BsE was also investigated. After one batch of reaction, the immobilized

Table 4 Enantioselective hydrolysis of dl-menthyl acetate at different substrate loads by immobilized BsE under the optimal reaction conditions

\begin{tabular}{lllll}
\hline Substrate loading & $\begin{array}{l}\text { Reaction } \\
\text { time (h) }\end{array}$ & ee $_{\mathbf{p}}$ (\%) & Conversion (\%) & E value \\
\hline $1.0 \mathrm{M} / 198 \mathrm{~g} \mathrm{I}^{-1}$ & 48 & 97 & 43 & 158 \\
$2.0 \mathrm{M} / 396 \mathrm{~g} \mathrm{I}^{-1}$ & 54 & 97 & 43 & 158 \\
$3.0 \mathrm{M} / 594 \mathrm{~g} \mathrm{I}^{-1}$ & 72 & 97 & 40 & 120
\end{tabular}

The reactions were performed at $30^{\circ} \mathrm{C}$ and $300 \mathrm{rpm}$ for $48 \mathrm{~h}$ by adding different concentrations of $d$-menthyl acetate, $0.55 \mathrm{~g}$ immobilized $\mathrm{BsE}$, and $25 \mathrm{mg}$ of SDS into a mixture of $8 \mathrm{ml} \mathrm{KPB}(\mathrm{pH} 8.0,200 \mathrm{mM})$ and $2 \mathrm{ml}$-pentanol. 


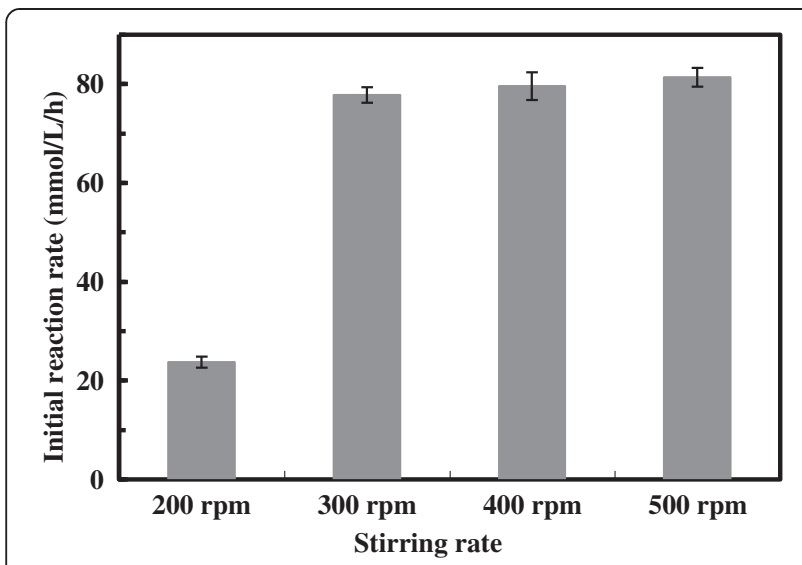

Figure 2 Initial rate of $d l$-menthyl acetate hydrolysis at various stirring rates in biphasic pentanol-buffer system. The reactions were performed at $30^{\circ} \mathrm{C}$ and varied stirring rates, by adding $0.55 \mathrm{~g}$ immobilized BsE and $25 \mathrm{mg}$ SDS into a mixture of $8 \mathrm{ml} \mathrm{KPB} \mathrm{(pH} \mathrm{8.0,}$ $200 \mathrm{mM}$ ) and $2 \mathrm{ml} \mathrm{n}$-pentanol.

enzyme was collected by filtration and reused in the next cycle. It should be noted that no activity was detected in the filtrated aqueous phase. After three batches of reaction, the initial reaction rate decreased to $45 \%$, as shown in Figure 3. As compared with the $8 \%$ deactivation after 10 cycles of reaction in mono-aqueous phase [25], the fast deactivation might be attributed to the proteindenaturing role of the anionic surfactant SDS.

\section{Preparation of $l$-menthol at decagram scale}

To evaluate the feasibility of the biocatalytic process for practical application, the BsE-mediated reaction was scaled up to $100 \mathrm{ml}$, with a substrate load of $3 \mathrm{M}\left(594 \mathrm{~g} \mathrm{l}^{-1}\right)$. The

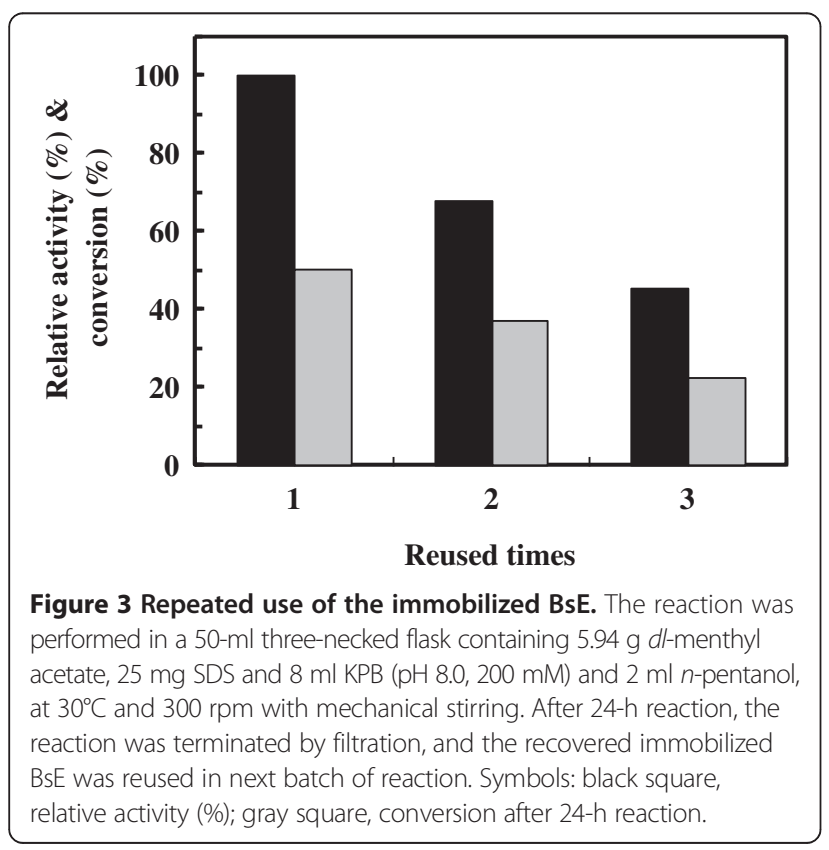

biocatalytic process was identical to that at $10-\mathrm{ml}$ scale, reaching $41 \%$ conversion after $84 \mathrm{~h}$ with an $e_{\mathrm{p}}$ of $97 \%$. After the reaction was terminated, the reaction mixture was filtrated under vacuum. The filtrate was divided into two phases immediately, without forming any emulsion which is frequently encountered in the case of free enzyme-catalyzed reactions. The organic phase was separated, then the solvent was removed by vacuum distillation, and finally the crude product was further purified by silica gel column chromatography, affording $17.3 \mathrm{~g}$ $l$-menthol $(97.2 \%$ ee), in a yield of $37 \%$ (the theoretical yield is $50 \%$ at maximum). Therefore, the biocatalytic process developed herein should be feasible for efficient transformation of highly loaded $d l$-menthyl acetate, demonstrating a good prospect for practical application in $l$-menthol manufacturing.

\section{Conclusions}

It has been proven that the use of immobilized BsE as a robust biocatalyst can perfectly catalyze the enantioselective hydrolysis of $d l$-menthyl acetate. In order to increase the substrate loading and to diminish the inhibition of enzyme activity by the product, an organic-aqueous two-phase system was adopted. To address the enantioselectivity decrease issue, several surfactants were tested for improving the mass transfer limitation between the two phases. Unexpectedly, anionic surfactant SDS as an additive could enhance the enantioselectivity from 26 to more than 150. By adopting these strategies, a high-performance bioprocess was successfully constructed for preparative synthesis of $l$ menthol with $97 \%$ ee. The substrate loading was as high as $3 \mathrm{M}\left(594 \mathrm{~g} \mathrm{l}^{-1}\right)$, affording a very high space-time yield of $198 \mathrm{~g}_{\text {-menthol }} \mathrm{l}^{-1}$ day $^{-1}$. Compared with the reported enantioselective enzymatic esterification of $d l$-menthol [19-21] and hydrolysis of $d l$-menthyl propionate [22], the substrate loading was much higher. These results inspire us to explore the possibility of industrial biocatalysis in large-scale production of $l$-menthol.

\section{Competing interests}

The authors declare that they have no competing interest.

\section{Authors' contributions}

G-WZ designed the study and responsible for the revision of the manuscript. Professors J-HX and QY provided the experimental guidance and manuscript revision. JP, N-DD, and BC conducted the experiments and JP drafted the manuscript. All authors read and approved the final manuscript.

\section{Acknowledgements}

The financial supports by the Ministry of Science and Technology, P.R. China (Nos. 2011AA02A210 and 2011CB710800), and the Open Fund of State Key Laboratory of Bioreactor Engineering (2060204), are gratefully acknowledged.

\section{Author details}

'Laboratory of Biocatalysis and Synthetic Biotechnology, State Key Laboratory of Bioreactor Engineering, East China University of Science and Technology, 130 Meilong Road, Shanghai 200237, China. ${ }^{2}$ Sunflower Pharmaceutical Group Company Limited, 85 Sihuan Road, Chongqing 408000, China. 
Received: 19 April 2014 Accepted: 4 August 2014

Published online: 30 September 2014

\section{References}

1. Clark GS (1998) Menthol. Perfum Flavor 23:33-46

2. Clark GS (2007) Aroma chemical profile: menthol. Perfum Flavor 32:38-47

3. Rendler S, Auer G, Keller M, Oestreich M (2006) Preparation of a privileged silicon-stereogenic silane: classical versus kinetic resolution. Adv Synth Catal 348:1171-1182

4. Cattaruzza F, Fares V, Flamini A, Prosperi T (2006) Synthesis of enantiomeric menthol derivatives for forming and probing chiral surfaces. X-ray crystal and molecular structures of (+)-(1S,2R,5S)-1-(2-tricyanovinyl-1H-pyrrol-1-ylmethoxy)-2-isopropyl-5-methylcycl-ohexane. Tetrahedron-Asymmetry 17:1296-1300

5. Michael M (2010) Hot market for a cool chemical. Chem Eng News 88:15-16

6. Fleischer J, Bauer K, Hopp R (1976) Separating optically pure $d$-l-isomers of menthol, neomenthol and isomenthol. US Patent 3,943,181,

7. Hopp R, Lawrence BM (2006) Natural \& synthetic menthol. In: Lawrence BM (ed) Mint: the genus Mentha. CRC, Boca Raton, p 389

8. Tani K (1985) Asymmetric isomerization of allylic compounds and the mechanism. Pure Appl Chem 57:1845-1854

9. Akutagawa S (1997) Enantioselective isomerization of allylamine to enamine: practical asymmetric synthesis of (-)-menthol by Rh-BINAP catalysts. Top Catal 4:271-274

10. Akutagawa S (1995) Asymmetric synthesis by metal BINAP catalysts. Appl Catal A-Gen 128:171-207

11. Sumi K, Kumobayashi H (2004) Rhodium/Ruthenium applications. Top Organomet Chem 6:63-95

12. Chaplin JA, Gardiner NS, Mitra RK (2006) Process for preparing (-)-menthol and similar compounds. US Patent 7,026,144

13. Brad D, Reddy S, Mboniswa B, Steenkamp LH, Rousseau AL, Parkinson CJ, Chaplin J, Mitra RK, Moutlana T, Marais SF, Gardiner NS (2012) Biocatalytic enantiomeric resolution of $\mathrm{l}$-menthol from an eight isomeric menthol mixture through transesterification. J Mol Catal B-Enzym 75:1-10

14. Xu JH, Kawamoto T, Tanaka A (1995) Efficient kinetic resolution of dl-menthol by lipase-catalyzed enantioselective esterification with acid anhydride in fed-batch reactor. Appl Microbiol Biotechnol 43:402-407

15. Ngo-Thi MT, Yin JG, Pan J, Zheng GW, Xu JH (2013) Enantioselective hydrolysis of dl-menthyl benzoate by cell-free extract of newly isolated Acinetobacter sp. ECU2040. Appl Biochem Biotechnol 170:1974-1981

16. Wang DL, Nag A, Lee GC, Shaw JF (2002) Factors affecting the resolution of $d$-menthol by immobilized lipase-catalyzed esterification in organic solvent. J Agric Food Chem 50:262-265

17. Vorlova S, Bornscheuer UT, Gatfield I, Hilmer JM, Bertram HJ, Schmid RD (2002) Enantioselective hydrolysis of D, L-menthyl benzoate to L-(-)-menthol by recombinant Candida rugosa lipase L1P1. Adv Synth Catal 344:1152-1155

18. Yu LJ, Xu Y, Wang XQ, Yu XW (2007) Highly enantioselective hydrolysis of DL-menthyl acetate to L-menthol by whole-cell lipase from Burkholderia cepacia ATCC25416. J Mol Catal B-Enzym 47:149-154

19. Meng Y, Wu JP, Xu G, Yang LR (2010) Production of L-menthol by immobilized enzyme-catalyzed diastereoselective transesterification. Chin $J$ Bioprocess Eng 8:39-44

20. Ren MY, Bai S, Sun Y (2009) Resolution of ( \pm )-menthol in ionic liquid catalyzed by immobilized lipase on magnetic microspheres. Chin $J$ Bioprocess Eng 7:16-20

21. Xu JH, Zhu J, Takuo K, Atsuo T, Hu Y (1997) Comparison of acid anhydrides with carboxylic acids in enantioselective enzymatic esterification of racemic menthol. Chin J Biotechnol 13:387-393

22. Xu G, Li M, Sun MM, Wu JP, Yang LR (2013) Screening of stereoselective lipase and its application in resolution of menthol. Chin J Bioprocess Eng $11: 1-4$

23. Zheng GW, Yu HL, Zhang JD, Xu JH (2009) Enzymatic production of I-menthol by a high substrate concentration tolerable esterase from newly isolated Bacillus subtilis ECU0554. Adv Synth Catal 351:405-414

24. Zheng GW, Pan J, Yu HL, Ngo-Thi MT, Li CX, Xu JH (2010) An efficient bioprocess for enzymatic production of $I$-menthol with high ratio of substrate to catalyst using whole cells of recombinant E. coli. J Biotechnol 150:108-114

25. Zheng GW, Yu HL, Li CX, Pan J, Xu JH (2011) Immobilization of Bacillus subtilis esterase by simple cross-linking for enzymatic resolution of $\mathrm{dl}$-menthyl acetate. J Mol Catal B-Enzym 70:138-143
26. Zhang ZJ, Pan J, Liu JF, Xu JH, He YC, Liu YY (2011) Significant enhancement of (R)-mandelic acid production by relieving substrate inhibition of recombinant nitrilase in toluene-water biphasic system. J Biotechnol 152:24-29

27. Li YG, Xing JM, Xiong XC, Li WL, Gao HS, Liu HZ (2008) Improvement of biodesulfurization activity of alginate immobilized cells in biphasic systems. J Ind Microbiol Biotechnol 35:145-150

28. Liu YY, Xu JH, Hu Y (2000) Enhancing effect of Tween-80 on lipase performance in enantioselective hydrolysis of ketoprofen ester. J Mol Catal B-Enzym 10:523-529

29. Chen CS, Fujimoto Y, Girdaukas G, Sih CJ (1982) Quantitative analyses of biochemical kinetic resolutions of enantiomers. J Am Chem Soc 104:7294-7299

30. Wang LJ, Li CX, Ni Y, Zhang J, Liu X, Xu JH (2011) Highly efficient synthesis of chiral alcohols with a novel NADH-dependent reductase from Streptomyces coelicolor. Bioresour Technol 102:7023-7028

31. Ni Y, Li CX, Wang LJ, Zhang J, Xu JH (2011) Highly stereoselective reduction of prochiral ketones by a bacterial reductase coupled with cofactor regeneration. Org Biomol Chem 9:5463-5468

32. Mori S, Yumoto H, Matsumi R, Nishigaki T, Ebara Y, Ueji S (2005) A method to greatly improve the enantioselectivity of lipase-catalyzed hydrolysis using sodium dodecyl sulfate (SDS) as an additive. Tetrahedron: Asymmetry 16:3698-3702

doi:10.1186/s40643-014-0012-x

Cite this article as: Pan et al:: Efficient production of $l$-menthol in a two-phase system with SDS using an immobilized Bacillus subtilis esterase. Bioresources and Bioprocessing 2014 1:12.

\section{Submit your manuscript to a SpringerOpen ${ }^{\odot}$ journal and benefit from:}

- Convenient online submission

- Rigorous peer review

- Immediate publication on acceptance

- Open access: articles freely available online

- High visibility within the field

- Retaining the copyright to your article

Submit your next manuscript at $>$ springeropen.com 